\title{
Microstructure and Magnetic Properties of La-Ca-Co Substituted M-Type Sr-Hexaferrites with Controlled Si Diffusion
}

\author{
Kyoung-Seok Moon ${ }^{1}$ (D), Pyeong-yeol $\mathrm{Yu}^{2}$ and Young-Min Kang ${ }^{2, *}$ \\ 1 Department of Materials Engineering and Convergence Technology, School of Materials Science and \\ Engineering, Gyeongsang National University, Jinju 52828, Korea; ksky.moon@gnu.ac.kr \\ 2 Department of Materials Science \& Engineering, Korea National University of Transportation, \\ Chungju 27469, Korea; pyeongyeol@ut.ac.kr \\ * Correspondence: ymkang@ut.ac.kr; Tel.: +82-43-841-5382
}

Received: 21 September 2020; Accepted: 26 October 2020; Published: 27 October 2020

\begin{abstract}
La-Ca-Co substituted M-type Sr-hexaferrites $\left(\mathrm{Sr}_{0.3} \mathrm{Ca}_{0.4} \mathrm{La}_{0.3} \mathrm{Fe}_{9.8} \mathrm{Co}_{0.2} \mathrm{O}_{19-\delta}\right)$ were prepared by a solid-state reaction using two different procedures, where the $\mathrm{SiO}_{2}$ additive was mixed either before calcination (pre-Si) or after calcination (post-Si). At the same sintering temperature, smaller cell volumes and reduced saturation magnetization $\left(M_{S}\right)$ values were obtained for samples processed with the pre-Si method than those with the post-Si method. This implied that the pre-Si method resulted in a greater degree of $\mathrm{Si}$ substitution into the M-type lattice and increased Fe extrusion out of the lattice. The grain growth behavior was controlled by the $\mathrm{SiO}_{2}$ amount and sintering temperature. It was found that abnormal grains occur with a bimodal distribution in the $0.5 \mathrm{wt} \% \mathrm{SiO}_{2}$ samples sintered at $1240{ }^{\circ} \mathrm{C}$, due to the increased critical driving force for growth caused by an increased amount of $\mathrm{SiO}_{2}$ addition. The $M_{S}$ and coercivity values were altered with the control of $\mathrm{Si}$ diffusion and abnormal grain growth. The control of the additive diffusion behavior is one of the important keys in the material design under same materials compositions.
\end{abstract}

Keywords: M-type hexaferrite; magnetic properties; microstructure; abnormal grain growth

\section{Introduction}

M-type (Ba, Sr)-hexaferrites are some of the most useful materials for permanent magnets [1]. Enhancing the magnetic and mechanical properties of these materials is economically important due to their widespread use across various global industries, such as consumer electronics and the electric automotive industry. Many studies have led to developments that have improved the intrinsic magnetic properties of Sr-hexaferrites, such as the saturation magnetization $\left(M_{S}\right)$ and crystalline anisotropy, by compositional design with elemental substitutions [2-7]. Among these, La-, Ca-, and Co-substitution of the M-type Sr-hexaferrites ( $\mathrm{La}-\mathrm{Ca}-\mathrm{Co}: \mathrm{SrM}$ ) is considered to be the most successful approach, leading to a significant enhancement in the crystalline anisotropy without reducing the $M_{s}[4,8]$. The resulting La-Ca-Co substituted M-type Sr-hexaferrites are thus high-grade ferrite magnets.

The coercivity $\left(H_{c}\right)$ is dependent on the grain size of the La-Ca-Co:SrM permanent magnets [9-11]. Grain growth behavior involves the movement of interfaces, including grain boundary structures, by interface reactions. This behavior can be controlled by adding dopants to alter the diffusion of atoms into the materials [12-14], adjusting the sintering temperature [15], and changing the oxygen partial pressure [16-18]. Generally, it has been understood that dopants change the microstructure of ceramics by suppressing grain growth and increasing densification [19]. These additive elements can segregate at grain boundaries and form a secondary solid or liquid phase and suppress the migration of interfaces and grain boundaries by the solute drag and Zener effects $[19,20]$. In the grain growth 
theory, grain growth behavior can be explained by the relationship between the critical driving force for grain growth $\left(\Delta g_{c}\right)$ and the maximum driving force for grain growth $\left(\Delta g_{\max }\right)$ in the two-dimensional nucleation grain growth mechanism [20-30]. Phenomenologically, grain growth behavior is divided into normal grain growth (invariable distribution of relative growth sizes with sintering time) and abnormal grain growth (some large grains grow quickly) $[17,20,22]$. The grain growth type can be changed by the value of $\Delta g_{c}$ relative to $\Delta g_{\max }$ during sintering [17,18,20,22]. The abnormal grain growth behavior can be calculated and explained exactly by the two-dimensional nucleation grain growth mechanism [22]. To the best of our knowledge, while a number of studies have analyzed the grain growth in M-type hexaferrites [6,23-27], no studies on La-Ca-Co:SrM grain growth have been reported. In the present study, the effects of $\mathrm{SiO}_{2}$ additives on the grain growth in La-Ca-Co:SrM were investigated. There are many previous studies on $\mathrm{Sr}$ hexaferrites with addition of $\mathrm{SiO}_{2}$ [12,31-34]. However, there has been no discussion of the position of Si elements regarding which Si element is in the lattice of grains or not.

The purpose of this study is to provide experimental support for the predicted effect of adding $\mathrm{SiO}_{2}$ and to determine the conditions that suppress the diffusion of $\mathrm{Si}$ into the crystalline lattice of the $\mathrm{Sr}_{0.3} \mathrm{Ca}_{0.4} \mathrm{La}_{0.3} \mathrm{Fe}_{9.8} \mathrm{Co}_{0.2} \mathrm{O}_{19-\delta}$ (SCLFCO) system. The specific molar fraction of the elements in SCLFCO was selected concerning the previous works $[3,7,8]$. The selective diffusion of Si should be controlled in order to increase $H_{c}$ without decreasing $M_{s}$.

\section{Materials and Methods}

$\mathrm{SiO}_{2}$-doped La-Ca-Co:SrM samples were prepared by a conventional solid-state reaction that employed two different procedures, referred to as pre-Si and post-Si. In the pre-Si method, precursor powders of $\mathrm{Fe}_{2} \mathrm{O}_{3}$ (99\%up, Kojundo Chemical Lab., Co., Ltd., Saitama Pre, Japan), $\mathrm{SrCO}_{3}$ (99.9\%, Kojundo Chemical Lab., Co., Ltd., Saitama Pre, Japan), $\mathrm{La}_{2} \mathrm{O}_{3}$ (99.9\%, Sigma-Aldrich, St. Louis, $\mathrm{MO}, \mathrm{USA}), \mathrm{CaCO}_{3}$ (99.9\%, Sigma-Aldrich, St. Louis, MO, USA), and $\mathrm{CoO}$ (98\%, Kojundo Chemical Lab., Co., Ltd., Saitama Pre, Japan) were weighed according to the target cation composition of $\mathrm{Sr}_{0.3} \mathrm{Ca}_{0.4} \mathrm{La}_{0.3} \mathrm{Fe}_{9.8} \mathrm{Co}_{0.2}$ and mixed together. Additionally, $\mathrm{SiO}_{2}(99.9 \%)$ was added to the mixture at a dose of $1 \mathrm{wt} \%$ of the total precursor powder. The powder mixture was ball-milled in water for $24 \mathrm{~h}$ using a polypropylene jar and yttria-stabilized $\mathrm{ZrO}_{2}$ balls with 3, 5, and $10 \mathrm{~mm}$ diameters. The dried slurry was calcined at $1100{ }^{\circ} \mathrm{C}$ in air for $4 \mathrm{~h}$. The calcined powders were crushed, ball-milled in water for $24 \mathrm{~h}$, dried, and pressed in a mold with a diameter of $15 \mathrm{~mm}$ at a pressure of $16.6 \mathrm{MPa}$ to produce a disk-shaped green compact pellet. The pelletized samples were sintered in air at a temperature range of $1200-1250^{\circ} \mathrm{C}$ for $2 \mathrm{~h}$. During the sintering process, the heating rate was $5^{\circ} \mathrm{C} / \mathrm{min}$ and the samples were then furnace-cooled to room temperature.

In the post-Si method, the same amount of $\mathrm{SiO}_{2}$ powder as used in the pre-Si method $(1 \mathrm{wt} \%$ of total precursor powder) was added before the second ball-milling process after calcination, as opposed to being added before the first ball-milling process before calcination. The target composition and all the other processes were the same as in the pre-Si method.

The density of the sintered sample was calculated based on the weight and geometric dimensions of the disk-shaped sample. The phase of the sintered samples was characterized using $X$-ray diffraction (XRD, D8 Advance, Bruker) with a Cu- $\mathrm{K}_{\alpha}$ radiation source $(\lambda=0.154056 \mathrm{~nm})$. The microstructures of the sintered samples were observed via field-emission scanning electron microscopy (FE-SEM, JSM-7610F, JEOL) of the fracture surfaces of the samples. Magnetization (M-H) curves of the sintered samples were measured using a vibrating sample magnetometer (VSM, 7410-S, Lake Shore) at room temperature with a sweeping magnetic field within $\pm 25 \mathrm{kOe}$.

\section{Results and Discussion}

Figure 1a-c show the XRD patterns of undoped (no-Si), pre-Si, and post-Si SCLFCO samples sintered at various temperatures. All no-Si SCLFCO samples were single phase M-type hexaferrites at all sintering temperatures $\left(1200-1250^{\circ} \mathrm{C}\right)$, with a hexagonal crystal structure and a space group of 
$\mathrm{P} 63 / \mathrm{mmc}$. On the other hand, when $1 \mathrm{wt} \% \mathrm{SiO}_{2}$ was added, a secondary phase of $\mathrm{Fe}_{2} \mathrm{O}_{3}$ appeared in all of the samples sintered at $1200-1250{ }^{\circ} \mathrm{C}$. Sharp peaks of $\mathrm{Fe}_{2} \mathrm{O}_{3}$ were found in the pre-Si samples at lower sintering temperatures, but were not observed in the post-Si samples. The substitution of Si into an Fe site could explain the appearance of an $\mathrm{Fe}_{2} \mathrm{O}_{3}$ solid phase. If $\mathrm{Si}$ diffused into the unit cell, then $\mathrm{Fe}$ would diffuse out and form $\mathrm{Fe}_{2} \mathrm{O}_{3}$.
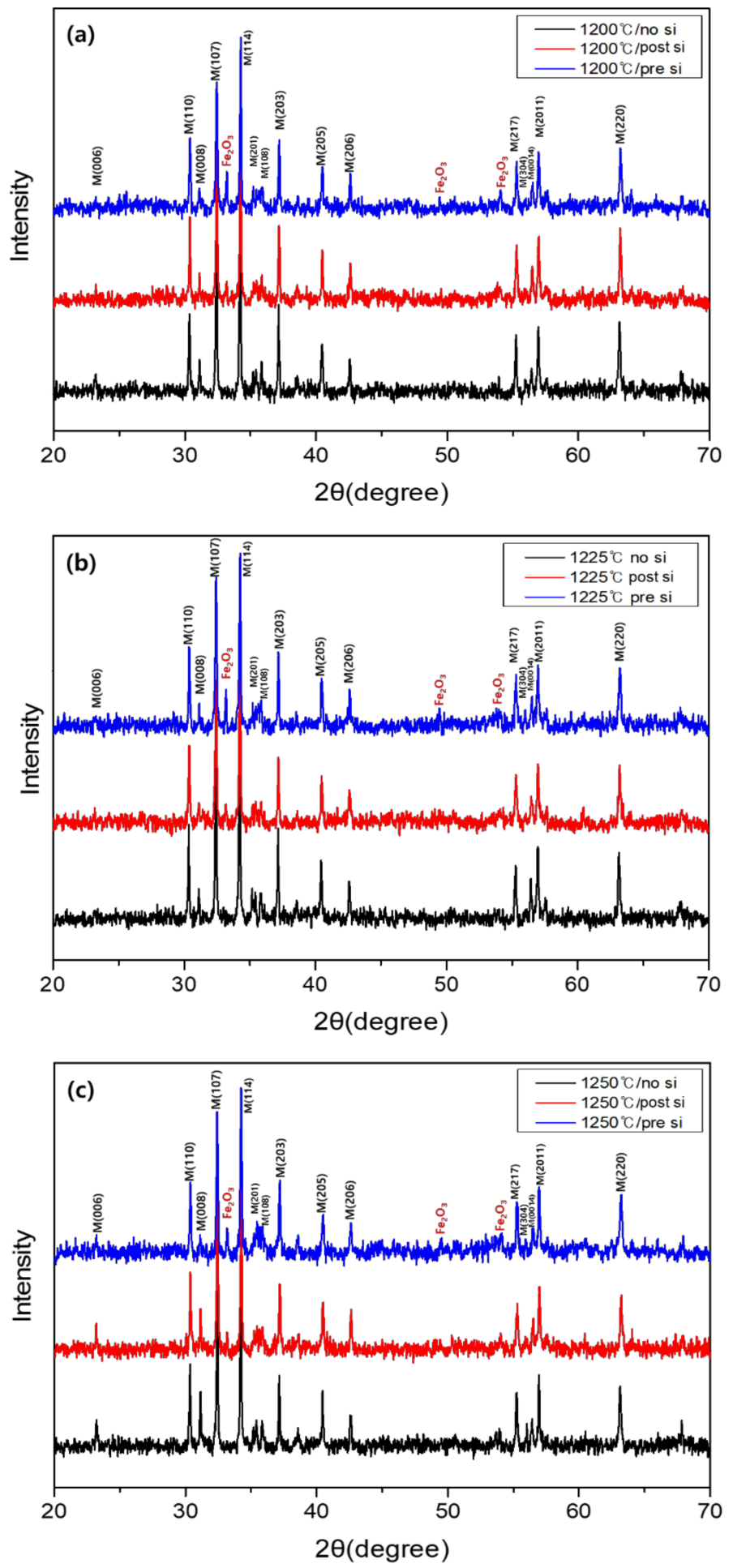

Figure 1. XRD patterns of no-Si, pre-Si, and post-Si SCLFCO samples sintered at $(\mathbf{a}) 1200^{\circ} \mathrm{C},(\mathbf{b}) 1225^{\circ} \mathrm{C}$, and (c) $1250^{\circ} \mathrm{C}$. 
Table 1 shows the cell volume of the SCLFCO hexaferrites, calculated based on XRD patterns (Jade 6.0, V6.2.9200, MDI, Materials Data, Inc., USA). For each sintering temperature, the cell volume was the highest in no-Si samples and the lowest in pre-Si samples. The change in cell volume could be the result of Si substitutions in Fe sites, as the ionic size of $\mathrm{Si}^{4+}$ is smaller than that of $\mathrm{Fe}^{3+}$ [35]. In addition, the observation that cell volumes of the pre-Si samples are smaller than those of the post-Si samples at each sintering temperature implies that a larger amount of Si was substituted into the hexaferrite lattice in the pre-Si method than in the post-Si method.

Table 1. Densities and unit cell volumes of sintered samples.

\begin{tabular}{cccc}
\hline $\begin{array}{c}\text { Sintering } \\
\text { Temperature }\end{array}$ & $\mathbf{1} \mathbf{~ w t} \mathbf{\%} \mathbf{~ S i O}_{\mathbf{2}}$ Addition & Density, $\mathbf{g} / \mathbf{c m}^{\mathbf{3}}$ & Unit Cell Vol., $\mathbf{A}^{\mathbf{3}}$ \\
\hline \multirow{2}{*}{$1200{ }^{\circ} \mathrm{C}$} & no-Si & 4.91 & 688.481 \\
& post-Si & 4.55 & 687.746 \\
& pre-Si & 4.78 & 687.518 \\
$1225{ }^{\circ} \mathrm{C}$ & no-Si & 4.89 & 689.005 \\
& post-Si & 4.72 & 688.073 \\
& pre-Si & 4.89 & 687.707 \\
$1250{ }^{\circ} \mathrm{C}$ & no-Si & 4.95 & 689.025 \\
& post-Si & 4.82 & 687.144 \\
& pre-Si & 4.93 & 686.250 \\
\hline
\end{tabular}

The excess $\mathrm{Fe}$ atoms form the $\mathrm{Fe}_{2} \mathrm{O}_{3}$ secondary phase, which could inhibit grain growth based on the Zener effect, where the movement of the interface and grain boundary is suppressed by a secondary phase on the interface and grain boundary $[19,20]$. When $\mathrm{Si}$ is added, a liquid phase can form, the structures of the interface and grain boundary can change, and the growth rate of each grain can be altered [14,20,22,28-30].

Figure 2a-i display SEM micrographs of no-Si, pre-Si, and post-Si SCLFCO samples sintered at various temperatures. The effect of the sintering temperature on the average grain size of each sample type is insignificant. However, the average grain size significantly decreased as $\mathrm{SiO}_{2}$ was added to all samples. The decrease in average grain size could be explained by the effect of $\mathrm{Fe}_{2} \mathrm{O}_{3}$ formation, as the $\mathrm{Fe}_{2} \mathrm{O}_{3}$ detected in the XRD patterns can suppress the migration of grain boundaries [19,20,24].

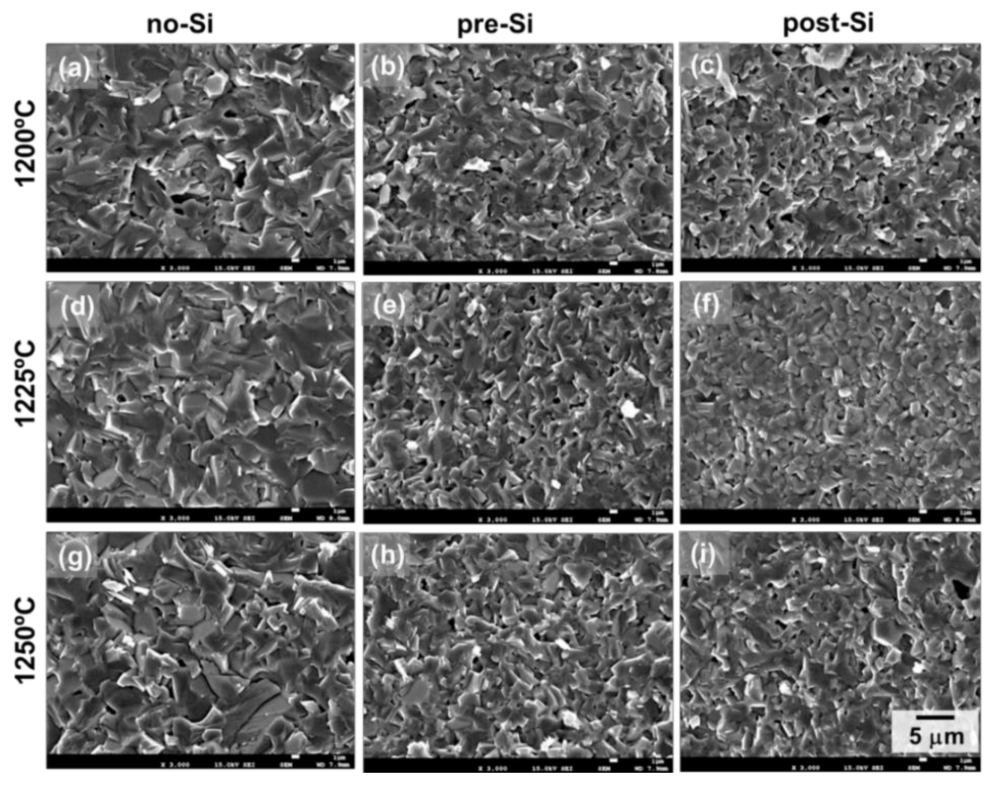

Figure 2. SEM micrographs of no-Si, pre-Si, and post-Si SCLFCO samples sintered at (a) $1200{ }^{\circ} \mathrm{C}$, (b) $1225^{\circ} \mathrm{C}$, and (c) $1250{ }^{\circ} \mathrm{C}$. 
The $H_{c}$ and other extrinsic properties may increase in samples with the addition of $\mathrm{SiO}_{2}$ due to a decrease in the average grain size [31,32]. However, the intrinsic properties, such as $M_{s}$, could also be changed due to the diffusion of $\mathrm{Si}$ into the lattice. The unit cell volumes of the samples with $\mathrm{SiO}_{2}$ addition were changed, as shown in Table 1 . This phenomenon can be explained by the diffusion of $\mathrm{Si}$ into unit cells which changed the intrinsic properties. As shown in Table 2, the degree of change in the $M_{S}$ in the pre-Si sample is larger than that in the post-Si sample. This could be due to the larger degree of $\mathrm{Si}$ substitution in the hexaferrite lattice in the pre-Si samples than that in the post-Si samples.

Table 2. $M_{S}$ and $H_{c}$ of sintered samples measured by vibrating sample magnetometer (VSM).

\begin{tabular}{cccc}
\hline Sintering Temperature & $\mathbf{1} \mathbf{w t} \mathbf{\%} \mathbf{S i O}_{\mathbf{2}}$ Addition & $\boldsymbol{H}_{\boldsymbol{c}}, \mathbf{O e}$ & $\boldsymbol{M}_{\boldsymbol{s}}, \mathbf{e m u} \mathbf{g}$ \\
\hline \multirow{2}{*}{$1200{ }^{\circ} \mathrm{C}$} & no-Si & 2272 & 68.01 \\
& post-Si & 3560 & 67.04 \\
& pre-Si & 3235 & 62.48 \\
$1225^{\circ} \mathrm{C}$ & no-Si & 2216 & 69.09 \\
& post-Si & 3581 & 65.37 \\
& pre-Si & 3293 & 63.26 \\
$1250{ }^{\circ} \mathrm{C}$ & no-Si & 2298 & 68.16 \\
& post-Si & 3400 & 64.98 \\
& pre-Si & 3351 & 64.85 \\
\hline
\end{tabular}

The microstructures in Figure 3 show that the coarsening behavior changes considerably with the addition of $\mathrm{SiO}_{2}$ during sintering at $1250{ }^{\circ} \mathrm{C}$. Here, all the samples were prepared with the pre-Si procedure but used different amounts of $\mathrm{SiO}_{2}$. The addition of $0.5 \mathrm{wt} \% \mathrm{SiO}_{2}$ caused an exaggerated, abnormal grain growth. In the samples with the addition of 1.0 and $2.0 \mathrm{wt} \% \mathrm{SiO}_{2}$, the grain size decreased compared to the case of the undoped and $0.5 \mathrm{wt} \% \mathrm{SiO}_{2}$-added sample. This cannot be explained with only the solute drag or Zener effects as the grain size should decrease due to these effects. According to the two-dimensional nucleation grain growth theory, abnormal grain growth can occur when the grain growth rate or migration of the interface is non-linear with $\Delta g$ and is governed by the interface reaction $[14,15,20,22,36-39]$. In previous studies, the abnormal grain growth phenomenon was observed in hexaferrites and the results and analyses support the theory of a non-linear grain growth rate [6,23-27]. During the sintering of inorganic materials, grain growth occurs due to the difference in pressure induced by interface curvature and a decrease in the total interface energy [20]. The driving force for the growth of a grain is given by $[20,22,39]$ :

$$
\Delta g=2 \gamma V_{m}\left(\frac{1}{r^{*}}-\frac{1}{r}\right)
$$

where $\gamma=$ interface energy, $V_{m}=$ molar volume, $r=$ radius of the grain of interest, and $r^{*}=$ critical grain radius or the radius of a grain that does not grow or shrink, and is similar to the average grain radius. Each grain has its own $\Delta g$ and the largest grain has a $\Delta g_{\max }$ as schematically shown in Figure $4 . \Delta g_{c}$ is the value that determines whether appreciable grain growth occurs in two-dimensional nucleation grain growth. The critical driving force for growth can be expressed by $[22,39]$

$$
\Delta g_{c}=\left(\frac{\pi \sigma^{2}}{k T h}\right) \ln K^{-1} \propto \frac{\sigma^{2}}{h}
$$

where $\sigma=$ step free energy, $h=$ height of the two-dimension nucleus, $k=$ Boltzmann constant, $T=$ absolute temperature, and $K$ is a constant that accounts for the diffusion coefficient and the number of nuclei per unit area. According to Equation (2), $\Delta g_{c}$ decreases as the sintering temperature increases and can be changed by altering the step free energy. The step free energy can be explained as the energy needed to form one layer and can be changed by the interface energy and structure [36]. $\Delta g_{c}$ can be 
altered by controlling the interface energy and structure among grains via changing temperature [15,23], adding a dopant $[14,38]$, or changing the sintering atmosphere [16,17].

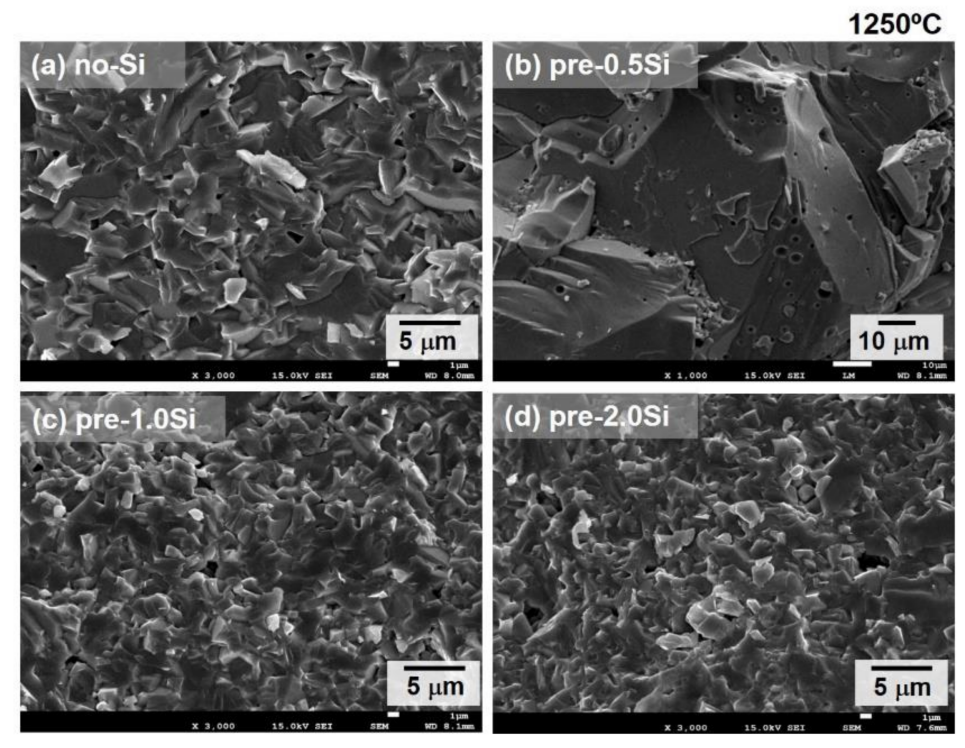

Figure 3. SEM micrographs of SCLFCO samples sintered at $1250{ }^{\circ} \mathrm{C}$ with varying amounts of $\mathrm{SiO}_{2}$ additions using the pre-Si method: (a) No-Si, (b) $0.5 \mathrm{wt} \%$, (c) $1.0 \mathrm{wt} \%$, and (d) $2.0 \mathrm{wt} \%$.
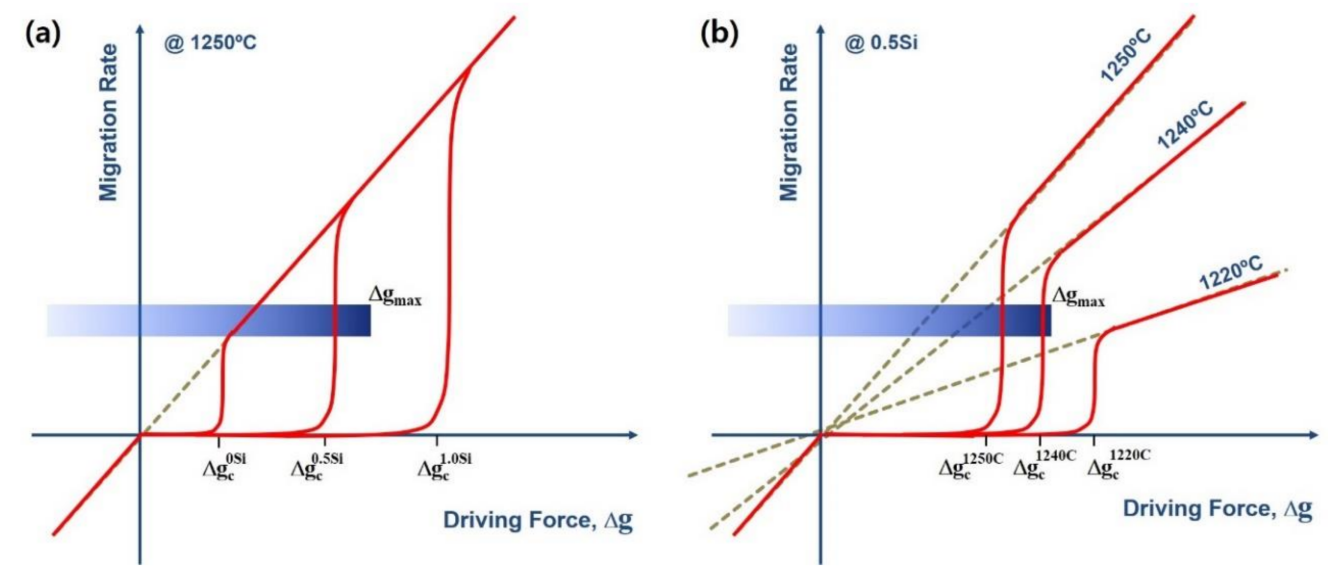

Figure 4. Schematic showing the growth rate of a crystal as a function of the driving force for diffusion (dashed lines) and a mix of diffusion and interface reaction control mechanisms (solid lines). (a) Plot of three mixed control curves for no-Si (0Si), $0.5 \mathrm{wt} \% \mathrm{SiO}_{2}(0.5 \mathrm{Si})$, and $1.0 \mathrm{wt} \% \mathrm{SiO}_{2}$ (1.0Si) SCLFCO samples sintered at the same temperature. (b) Plots of three mixed control curves for $0.5 \mathrm{wt} \% \mathrm{SiO}_{2}$ SCLFCO samples sintered at $1220^{\circ} \mathrm{C}, 1240^{\circ} \mathrm{C}$, and $1250^{\circ} \mathrm{C}$.

Figure 4 depicts the grain growth rate as a function of the $\Delta g$ for diffusion (dashed line) and interface reactions (solid line) according the Equations (1) and (2). In the case of the no-Si sample sintered at $1250{ }^{\circ} \mathrm{C}$, most grains can grow since the $\Delta g$ of the grains is larger than the $\Delta g_{c}$ for no-Si $\left(\Delta g_{c}{ }^{0 \mathrm{Si}}\right)$, as shown in Figure 4a. As the grain growth behavior changes with the addition of $\mathrm{SiO}_{2}$, the $\Delta g_{c}$ for appreciable grain growth increases when adding $\mathrm{SiO}_{2}$. This is similar to the phenomenon observed when $\mathrm{TiO}_{2}$ is added to sodium bismuth titanate [14]. As seen in Figure $4 \mathrm{a}$, when $0.5 \mathrm{wt} \%$ $\mathrm{SiO}_{2}$ was added using the pre-Si method (pre-0.5Si), $\Delta g_{c}{ }^{0.5 \mathrm{Si}}$ increased but is still lower than the $\Delta g_{\max }$. Therefore, some grains can grow rapidly and encroach on one another and Ostwald ripening can occur during the initial stage of sintering, where small grains are dissolved and absorbed into larger grains. Finally, grain growth stops in samples of pre-0.5Si. Figure 4a shows that as the amount of $\mathrm{SiO}_{2}$ increases, $\Delta g_{c}$ increases until it is greater than $\Delta g_{\max }$, resulting in no grain growth in the initial stage of 
sintering. The changes in the microstructure of samples with the addition of $\mathrm{SiO}_{2}$, as shown in Figure 3, are in line with the grain growth theory and are similar to previous studies on hexaferrites [24,26].

To confirm the non-linearity of the grain growth rate with $\Delta g$ and understand the microstructural changes in samples with $\mathrm{SiO}_{2}$ addition, the compacted powders of pre-Si samples with $0.5 \mathrm{wt} \% \mathrm{SiO}_{2}$ were sintered at various temperatures. The SEM images of these samples are shown in Figure 5. As seen in Figure $5 \mathrm{~b}$, a bimodal grain size distribution is observed in the sample sintered at $1240^{\circ} \mathrm{C}$; aside from a few grains that grew rapidly, most grains did not grow. No grain growth occurred in the samples sintered at $1200{ }^{\circ} \mathrm{C}$ and $1220^{\circ} \mathrm{C}$, resulting in a small grain size. In the grain growth theory, the $\Delta g_{c}$ increases and the diffusion rate decreases as the sintering temperature decreases $[20,22,39]$. The pore and grain shape are dependent on the interface (grain boundary and surface) structure [20,21]. The anisotropy of grain and pore increases as the fraction of the atomically ordered interface increases [14,21]. The $\Delta g_{c}$ increases as the fraction of the of the atomically ordered interface increases [14,18]. The spherical pore shape can explain that the anisotropy decreases and the $\Delta g_{c}$ decreases as the sintering temperature increases.
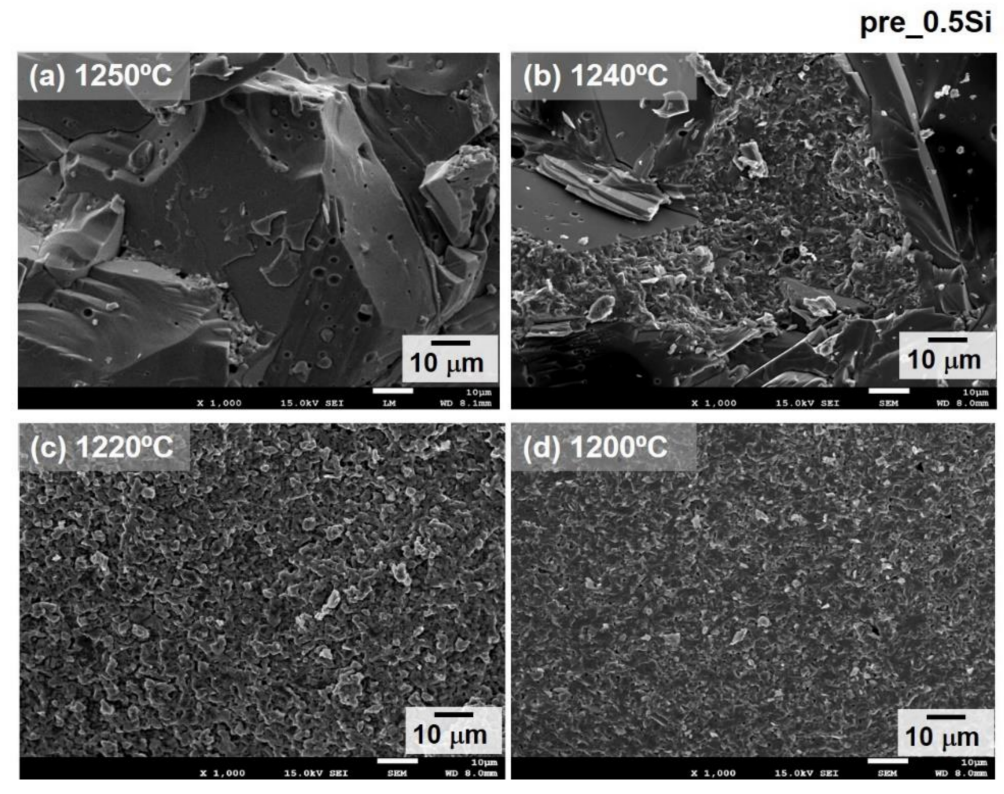

Figure 5. SEM micrographs of $0.5 \mathrm{wt} \% \mathrm{SiO}_{2}$ pre-Si SCLFCO samples sintered at (a) $1250{ }^{\circ} \mathrm{C},(\mathbf{b}) 1240{ }^{\circ} \mathrm{C}$, (c) $1220^{\circ} \mathrm{C}$, and (d) $1200^{\circ} \mathrm{C}$.

The slope of the dashed line in Figure $4 \mathrm{~b}$ decreases as the diffusion rate and sintering temperatures decrease [22]. As the sintering temperature decreases from $1250{ }^{\circ} \mathrm{C}$ to $1240{ }^{\circ} \mathrm{C}$, the $\Delta g_{c}$ increases and is closer to, but still below, $\Delta g_{\max }$. This results in an abnormal growth of a few grains with a $\Delta g$ greater than $\Delta g_{c}{ }^{1240 \mathrm{C}}$, while most grains cannot grow. Figure $4 \mathrm{~b}$ indicates that as the $\Delta g_{c}$ increases and the sintering temperature decreases, $\Delta g_{c}{ }^{1220 \mathrm{C}}$ becomes larger than $\Delta g_{\max }$. This results in no grain growth as none of the grains have a driving force for growth at the low sintering temperatures of $1200^{\circ} \mathrm{C}$ and $1220^{\circ} \mathrm{C}$. The abnormal grain growth phenomena of SCLFCO can be explained by the grain growth theory and observed via the addition of $\mathrm{SiO}_{2}$ and the change in sintering temperature. The grain growth mechanism of SCLFCO can be explained by the migration of the facet plane, consistent with previous studies [6,23-27].

The M-H curves of sintered samples are plotted in Figure 6a-c. The $M_{s}$ and $H_{c}$ values of these samples are presented in Table 2, where $M_{s}$ is the magnetization value at $H=25 \mathrm{kOe}$. Comparing samples sintered at the same temperature, the no-Si samples have the largest $M_{S}$ and the pre-Si samples have the smallest $M_{\mathcal{S}}$. These results show that a Si substitution into an Fe site in the hexaferrite matrix deteriorates the magnetism. Pre-Si samples have a lower $M_{S}$ value and a greater degree of substitution of $\mathrm{Si}$ than post-Si samples. However, the magnitude of the difference in $M_{s}$ among these samples is highly dependent on the sintering temperature. At a sintering temperature of $1200^{\circ} \mathrm{C}$, the $M_{S}$ of the 
post-Si sample is closer to that of the no-Si sample than that of the pre-Si sample, as the driving force of Si diffusion into the interior of the grains in the post-Si sample is not high enough to produce an appreciable effect. At a sintering temperature of $1250{ }^{\circ} \mathrm{C}$, the $M_{S}$ of the post-Si sample is closer to that of the pre-Si sample than that of the no-Si sample. These data show that the $\mathrm{Si}$ atom has a significantly higher driving force for diffusion at $1225^{\circ} \mathrm{C}$ than that at $1200{ }^{\circ} \mathrm{C}$. The driving force for diffusion is high enough to achieve full diffusion of $\mathrm{Si}$ at $1250^{\circ} \mathrm{C}$. It can be assumed that there is a homogeneous distribution of $\mathrm{Si}$ in the pre-Si grains and the $M_{S}$ values of pre-Si and post-Si samples are approximately the same. Concerning the $H_{c}$ of the samples, it was found that the post-Si method is more effective than the pre-Si method, as higher $H_{c}$ values were obtained for post-Si samples. However, both post-Si and pre-Si samples exhibit greatly enhanced values compared to no-Si samples. As shown in Figure 2, the average grain size between the samples prepared by pre-Si and post-Si methods is not significantly different. As previously mentioned, it was observed that $\mathrm{Si}$ substitution into Fe sites extrudes Fe out of the matrix and forms excess $\mathrm{Fe}_{2} \mathrm{O}_{3}$, which prohibits grain growth. The $H_{c}$ of the samples mostly depends on the grain size.
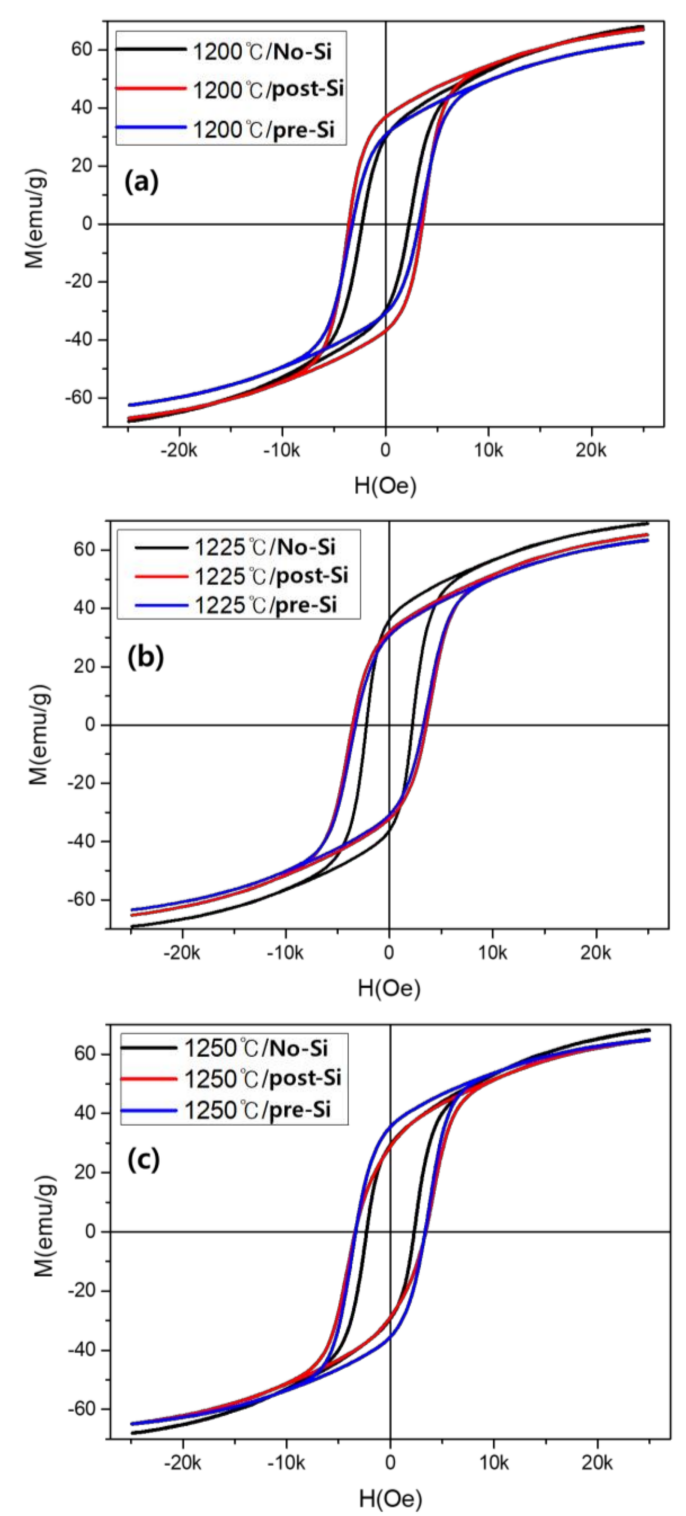

Figure 6. M-H curves of no-Si, pre-Si, and post-Si SCLFCO samples sintered at (a) $1220^{\circ} \mathrm{C},(\mathbf{b}) 1225^{\circ} \mathrm{C}$, and (c) $1250{ }^{\circ} \mathrm{C}$. 


\section{Conclusions}

The grain growth behaviors and magnetic properties of SCLFCO systems with $\mathrm{SiO}_{2}$ addition were investigated. Typically, when a dopant is added, the grain growth is suppressed by the solute drag and Zener effects. However, abnormal grain growth behavior of SCLFCO was observed by changing the sintering temperature and the amount of $\mathrm{SiO}_{2}$ added. Thus, the grain growth behavior cannot be explained solely based on the solute drag and Zener effects. The effects of Si addition on the intrinsic magnetic property, $M_{s}$, were studied by changing the processing procedure. It was shown that $\mathrm{Si}$ can diffuse into the unit cell and change the intrinsic properties. At the same sintering temperature, the cell volumes of the pre-Si samples were smaller than those of the post-Si samples, which meant that a larger amount of $\mathrm{Si}$ was substituted into the hexaferrite lattice in the pre-Si method. The grain growth behavior of $\mathrm{SCLFCO}$ with $\mathrm{SiO}_{2}$ addition can be explained by a two-dimensional nucleation grain growth mechanism with a non-linear relationship between the grain growth rate and the driving force for grain growth. As the amount of $\mathrm{SiO}_{2}$ increases, the critical driving force for grain growth increases, which results in abnormal grain growth with a bimodal distribution in the $0.5 \mathrm{wt} \% \mathrm{SiO}_{2}$ samples sintered at $1240{ }^{\circ} \mathrm{C}$. When more $\mathrm{SiO}_{2}$ was added, the critical driving force was larger than the driving force for growth of all grains, which resulted in no grain growth in the initial stage of sintering. The growth mechanism of SCLFCO can be explained by the migration of the facet plane with the two-dimensional nucleation grain growth mechanism. The magnetic properties of $M_{s}$ and $H_{c}$ can be altered through the control of the Si addition process and the abnormal grain growth in hexaferrites.

Author Contributions: Y.-M.K. and K.-S.M. designed the experiments. P.-y.Y. performed the experiments and analyzed the samples. K.-S.M. analyzed and explained the grain growth behaviors of the samples. All the authors discussed the data and wrote the manuscript. All authors have read and agreed to the published version of the manuscript.

Funding: This study was supported by the Research Fund of the Basic Science Research Program through the National Research Foundation of Korea, funded by the Ministry of Science, ICT, and Future Planning (Grant No. 2017R1C1B2002394). This study was supported by the materials and parts technology development (Grant No. 20010938), funded by the Ministry of Trade, Industry \& Energy (MoTIE, Korea).

Conflicts of Interest: The authors declare no conflict of interest.

\section{References}

1. Pullar, R.C. Hexagonal ferrites: A review of the synthesis, properties and applications of hexaferrite ceramics. Prog. Mater. Sci. 2012, 57, 1191. [CrossRef]

2. Bai, J.; Liu, X.; Xie, T.; Wei, F.; Yang, Z. The effects of La-Zn substitution on the magnetic properties of Sr-magnetoplumbite ferrite nano-particles. Mater. Sci. Eng. 2000, 68, 182-185. [CrossRef]

3. Ogata, Y.; Takami, T.; Kubota, Y. Development of La-Co Substituted Ferrite Magnets. J. Jpn. Soc. Powder Powder Metall. 2003, 50, 636-641. [CrossRef]

4. Kobayashi, Y.; Hosokawa, S.; Oda, E.; Toyota, S. Magnetic properties and composition of Ca-La-Co M-type ferrites. J. Jpn. Soc. Powder Powder Metall. 2008, 55, 541-546. [CrossRef]

5. Kang, Y.-M.; Kwon, Y.-H.; Kim, M.-H.; Lee, D.-Y. Enhancement of magnetic properties in Mn-Zn substituted M-type Sr-hexaferrites. J. Magn. Magn. Mater. 2015, 382, 10-14. [CrossRef]

6. Kang, Y.-M.; Moon, K.-S. Magnetic properties of Ce-Mn substituted M-type Sr-hexaferrites. Ceram. Int. 2015, 41, 12828-12834. [CrossRef]

7. Kang, Y.-M. High saturation magnetization in La-Ce-Zn-doped M-type Sr-hexaferrites. Ceram. Int. 2015, 41, 4354-4359. [CrossRef]

8. Kobayashi, Y.; Nishiuchi, T.; Oda, E.; Nakagawa, T. Cation distribution analysis of Ca-La-Co M-type ferrites by neutron diffraction, extended X-ray absorption fine structure and X-ray magnetic circular dichroism. J. Jpn. Soc. Powder Powder Metall. 2016, 63, 101-108. [CrossRef]

9. Nishio, H.; Minachi, Y.; Yamamoto, H. Effect of Factors on Coercivity in Sr-La-Co Sintered Ferrite Magnets. IEEE Trans. Magn. 2009, 45, 5281-5288. [CrossRef]

10. Sixtus, K.J.; Kronenberg, K.J.; Tenzer, R.K. Investigations on Barium Ferrite Magnets. J. Appl. Phys. 1956, 27, 1051-1057. [CrossRef] 
11. Kang, Y.-M.; Lee, J.; Kang, Y.J.; Park, J.-B.; Kim, S.I.; Lee, S.M.; Ahn, K. Understanding on coercivity behavior of M-type strontium hexaferrite through thin-film experiment and micromagnetic modeling. Appl. Phys. Lett. 2013, 103, 122407. [CrossRef]

12. Park, C.W.; Yoon, D.Y. Effects of $\mathrm{SiO}_{2}, \mathrm{CaO}_{2}$, and $\mathrm{MgO}$ additions on the grain growth of alumina. J. Am. Ceram. Soc. 2000, 83, 2605-2609. [CrossRef]

13. Fisher, J.G.; Kim, M.S.; Lee, H.Y.; Kang, S.-J.L. Effect of $\mathrm{Li}_{2} \mathrm{O}$ and $\mathrm{PbO}$ additions on abnormal grain growth in the $\mathrm{Pb}\left(\mathrm{Mg}_{1 / 3} \mathrm{Nb}_{2 / 3}\right) \mathrm{O}_{3}-35 \mathrm{~mol} \% \mathrm{PbTiO}_{3}$ system. J. Am. Ceram. Soc. 2004, 87, 937-942. [CrossRef]

14. Moon, K.-S.; Rout, D.; Lee, H.-Y.; Kang, S.-J.L. Effect of $\mathrm{TiO}_{2}$ addition on grain shape and grain coarsening behavior in $95 \mathrm{Na}_{1 / 2} \mathrm{Bi}_{1 / 2} \mathrm{O}_{3}-\mathrm{BaTiO}_{3}$. J. Eur. Ceram. Soc. 2011, 31, 1915-1920. [CrossRef]

15. Cho, K.; Yoon, D.Y.; Kim, B.K. Surface roughening transition and coarsening of $\mathrm{NbC}$ grains in liquid cobalt-rich matrix. J. Am. Ceram. Soc. 2004, 87, 443-448. [CrossRef]

16. Lee, B.K.; Chung, S.Y.; Kang, S.-J.L. Grain boundary faceting and abnormal grain growth in BaTiO3. Acta Mater. 2000, 48, 1575-1580. [CrossRef]

17. Jung, Y.-I.; Choi, S.Y.; Kang, S.-J.L. Effect of oxygen partial pressure on grain boundary structure and grain growth behavior in $\mathrm{BaTiO}_{3}$. Acta Mater. 2006, 54, 2849-2855. [CrossRef]

18. Fisher, J.G.; Rout, D.; Moon, K.-S.; Kang, S.-J.L. Structural changes in potassium sodium niobate ceramics sintered in different atmospheres. J. Alloy. Compd. 2009, 479, 467-472. [CrossRef]

19. Boutz, M.M.R.; Winnubst, A.J.A.; Burggraaf, A.J. Yttria-ceria stabilized tetragonal zirconia polycrystals: Sintering, grain growth and grain boundary segregation. J. Eur. Ceram. Soc. 1994, 13, 89-102. [CrossRef]

20. Kang, S.-J.L. Sintering: Densification, Grain Growth and Microstructure; Elsevier Butterworth-Heinemann: Oxford, UK, 2005.

21. Howe, J.M. Interfaces in Materials, 1st ed.; John Wiley \& Sons: New York, NY, USA, 1997.

22. Jung, Y.I.; Yoon, D.Y.; Kang, S.-J.L. Coarsening of polyhedral grains in a liquid matrix. J. Mater. Res. 2009, 24, 2949-2959. [CrossRef]

23. Moon, K.-S.; Kang, Y.-M.; Han, I.; Lee, S.-E. Grain growth behavior of $\mathrm{Ba}_{1.5} \mathrm{Sr}_{1.5} \mathrm{Co}_{2} \mathrm{Fe}_{24} \mathrm{O}_{41}$ flakes in molten salt synthesis and the magnetic properties of flake/polymer composites. J. Appl. Phys. 2016, 120, 194102. [CrossRef]

24. Moon, K.-S.; Kang, Y.-M. Structural and magnetic properties of Ca-Mn-Zn-substituted M-type Sr-hexaferrites. J. Eur. Ceram. Soc. 2016, 36, 3383-3389. [CrossRef]

25. Fisher, J.G.; Sun, H.; Kook, Y.-G.; Kim, J.-S.; Le, P.G. Growth of single crystals of $\mathrm{BaFe}_{12} \mathrm{O}_{19}$ by solid state crystal growth. J. Magn. Magn. Mater. 2016, 416, 384-390. [CrossRef]

26. Moon, K.-S.; Kang, Y.-M. Synthesis, structure, and magnetic properties of M-W hexaferrite composites. Ceram. Int. 2017, 43, 14309-14313. [CrossRef]

27. Moon, K.-S.; Lim, E.-S.; Kang, Y.-M. Effect of Ca and La substitution on the structure and magnetic properties of M-type Sr-hexaferrites. J. Alloy. Compd. 2019, 771, 350-355. [CrossRef]

28. Park, Y.J.; Hwang, N.M.; Yoon, D.Y. Abnormal growth of faceted (WC) grains in a (Co) liqiud matrix. Metall. Mater. Trans. A Phys. Metall. Mater. Sci. 1996, 27, 2809-2819. [CrossRef]

29. Rohrer, G.S.; Rohrer, C.L.; Mullins, W.W. Coarsening of faceted crystals. J. Am. Ceram. Soc. 2002, 85, 675-682. [CrossRef]

30. Choi, S.Y.; Kang, S.-J.L.; Chung, S.Y. Abnormal grain growth and intergranular amorphous film formation in $\mathrm{BaTiO}_{3}$. J. Am. Ceram. Soc. 2007, 90, 645-648. [CrossRef]

31. Töpfer, J.; Schwarzer, S.; Senz, S.; Hesse, D. Influence of $\mathrm{SiO}_{2}$ and $\mathrm{CaO}$ additions on the microstructure and magnetic properties of sintered Sr-hexaferrite. J. Eur. Ceram. Soc. 2005, 25, 1681-1688. [CrossRef]

32. Taguchi, H.; Hirata, F; Takeishi, T. Effect of $\mathrm{SiO}_{2}-\mathrm{SrCO}_{3}$ Addition on Magnetic Properties of Anisotropic Ba-ferrite (Ferrite Magnets Having Equal Shrinkage Ratio in A-axis and C-axis). J. Jpn. Soc. Powder Powder Metall. 1996, 43, 19-24. [CrossRef]

33. Hussain, S.; Anis-ur-Rehman, M.; Maqsood, A.; Awan, M.S. The effect of $\mathrm{SiO}_{2}$ addition on structural, magnetic and electrical properties of strontium hexaferrites. J. Cryst. Growth 2006, 297, 403-410. [CrossRef]

34. Huang, C.C.; Jiang, A.H.; Hung, Y.H.; Liou, C.H.; Wang, Y.C.; Lee, C.P.; Hung, T.Y.; Shaw, C.C.; Kuo, M.F.; Cheng, C.H. Influence of $\mathrm{CaCO}_{3}$ and $\mathrm{SiO}_{2}$ additives on magnetic properties of M-type Sr-ferrites. J. Magn. Magn. Mater. 2018, 451, 288-294. [CrossRef]

35. Weast, R.C. (Ed.) CRC Handbook of Chemistry and Physics, 68th ed.; CRC Press: Boca Raton, FL, USA, 1987; p. F-159. 
36. Yoon, D.Y.; Park, C.W.; Koo, J.B. The Step Growth Hypothesis for Abnormal Grain Growth. In Ceramic Interfaces 2; Yoo, H.-I., Kang, S.-J.L., Eds.; Maney Publishing: London, UK, 2001; pp. 3-21.

37. Fisher, J.G.; Choi, S.Y.; Kang, S.-J.L. Abnormal grain growth in barium titanate doped with alumina. J. Am. Ceram. Soc. 2006, 89, 2206-2212. [CrossRef]

38. Kim, M.S.; Fisher, J.G.; Kang, S.-J.L.; Lee, H.Y. Grain growth control and solid-state crystal growth by $\mathrm{Li}_{2} \mathrm{O} / \mathrm{PbO}$ addition and dislocation introduction in the PMN-35PT system. J. Am. Ceram. Soc. 2006, 89, 1237-1243. [CrossRef]

39. Kang, S.-J.L.; Lee, M.G.; An, S.M. Microstructural evolution during sintering with control of the interface structure. J. Am. Ceram. Soc. 2009, 92, 1464-1471. [CrossRef]

Publisher's Note: MDPI stays neutral with regard to jurisdictional claims in published maps and institutional affiliations.

(C) 2020 by the authors. Licensee MDPI, Basel, Switzerland. This article is an open access article distributed under the terms and conditions of the Creative Commons Attribution (CC BY) license (http://creativecommons.org/licenses/by/4.0/). 